Muhammad Farid Yuanda, Dasman Lanin I Efektivitas Program Kerja Institusi Penerima Wajib Lapor (IPWL) dalam Rehabilitasi Pecandu Narkotika di Kabupaten Agam

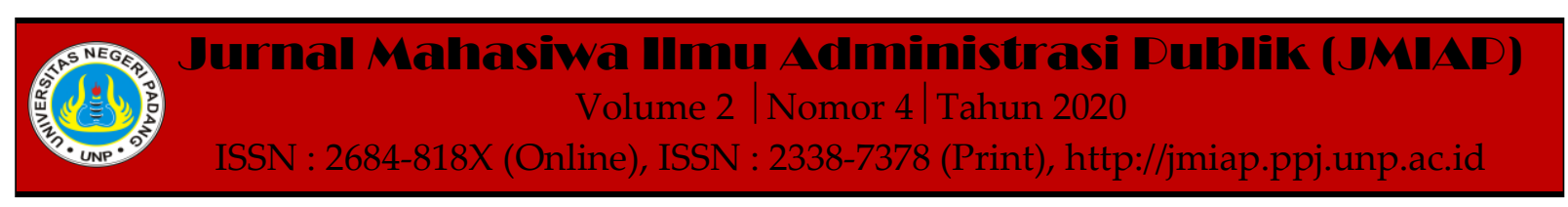

\title{
EFEKTIVITAS PROGRAM KERJA INSTITUSI PENERIMA WAJIB LAPOR (IPWL) DALAM REHABILITASI PECANDU NARKOTIKA DI KABUPATEN AGAM
}

\author{
Muhammad Farid Yuanda ${ }^{1(a)}$, Dasman Lanin ${ }^{2(b)}$ \\ ${ }^{1}$ Jurusan Ilmu Administrasi Negara, Universitas Negeri Padang \\ ${ }^{2}$ Jurusan Ilmu Administrasi Negara, Universitas Negeri Padang \\ a)faridyuanda3@gmail.com, ${ }^{b}$ dasman@fis.unp.ac.id
}

\begin{abstract}
This article aims to describe the Effectiveness of The Work Program of Mandatory Reporting Institutions (IPWL) in the Rehabilitation of Narcotics Addicts in Agam Regency. This research uses descriptive qualitative method. The location of the research was conducted in Agam Regency precisely on Jln. Surau Usang, Jorong Parit Putus, Nagari Ampang Gadang, District IV Angkek.Informan research determined purposive sampling. This research data is obtained from interviews, observations, and documentation studies. Data validity test is done by trianggulasi source then data analyzed by reducing data, display data and drawing conclusions during the research. The results obtained after conducting the research, namely the Effectiveness of the Labor Compulsory Recipient Institution Work Program (IPWL) in the Rehabilitation of Narcotics Addicts in Agam District have been considered effective because it is successful in carrying out social rehabilitation activities of drug addicts. However, if assessed in terms of efficiency can be said still not optimal. In fact, drug addicts have stopped using drugs after completing rehabilitation activities at IPWL. However, they still have obstacles to re-mingle with the community as well as activities as usual, because of the image of an addict who is inherent and burdensome.
\end{abstract}

Keywords : Effectiveness, IPWL Program, Rehabilitation of Narcotics Addicts

Corresponding author. Email.faridyuanda3@gmail.com

How to cite this article. Yuanda, M. Farid \& Lanin, Dasman. (2020). Efektivitas Program Kerja Institusi Penerima Wajib Lapor (IPWL) dalam Rehabilitasi Pecandu Narkotika di Kabupaten Agam. Jurnal Mahasiwa Ilmu Administrasi Publik (JMIAP) Jurusan Ilmu Administrasi Negara Fakultas Ilmu Sosial Universitas Negeri Padang, Volume 2 (4), Hal. 62-69.

http://jmiap.ppj.unp.ac.id

ISSN : 2684-818X (Online), ISSN : 2338-7378 (Print)

Copyright $\odot 2020$. Published by Labor Jurusan Ilmu Administrasi Negara FIS UNP, Padang 


\section{PENDAHULUAN}

Rehabilitasi adalah program untuk membantu menyembuhkanseseorang dengan penyakit akut, baik secara fisik ataupun psikologis. Ini juga merupakan rangkaian dari upaya untuk meningkatkan kapasitas adaptasi diri, otonomi, swadaya serta mencapai kemampuan fungsional berdasarkan potensi fisik, mental, sosial dan ekonominya. Dengan demikian, dalam mengatasi masalah penyalahgunaan narkoba dapat berinteraksi secara adil dengan masyarakat.

Dalam Undang-Undang Nomor 35 Tahun 2009 pasal 54-58 tentang narkotika adalah korban penyalahgunaan narkotika wajib menjalani rehabilitasi medis dan sosial yang diselenggarakan oleh instansi pemerintah maupun masyarakat. Pemerintah mengeluarkan peraturan pemerintah nomor 25 tahun 2011 tentang pelaksanaan wajib lapor bagi pecandu narkotika yang disebut IPWL. IPWL didasarkan oleh Keputusan Menkes RI No.18/Menkes/SK/VII/2012,

yangbertujuan mengajak pecandu narkobauntukdirehabilitasi sehingga bisa terhindar dari jeratan hukum.Di sini juga tersedia rawat inap dan rawat jalan bagi korban penyalahgunaan narkotika tersebut.

Sama kita ketahui pecandu narkoba di Sumatera Barat saat ini telah mencapai 66.612 orang baik golongan coba pakai, teratur, maupun pecandu. Dari data tersebut dapat di ketahui bahwasanya pengguna narkoba di sumatera sangat banyak dan meningkat setiap tahunnya, maka dari itu pada tahun 2012 pemerintah bekerja sama dengan kemenkes untuk mengeluarkan program yang dinamakan IPWL (Institusi Penerima Wajib Lapor). Dengan adanya program IPWL tersebut di harapkan dapat meminimalisir pengguna dan pecandu narkoba di Sumatera Barat.

Program Institusi Penerima Wajib Lapor (IPWL) sendiri dilaksanakan disebuah lembaga kesehatan maupun sosial yang ditetapkan oleh pemerintah yang secara khusus dipersiapkan untuk melaksanakan program tersebut.Lokasi IPWL yang tersebar ditengah masyarakat mempermudah akses pelayanan program wajib lapor sehingga pelaksanaan menjadi lebih efektif.Di Sumatera Barat terdapat beberapa lembaga IPWL yang ditetapkan oleh pemerintah, termasuk IPWL Agam Solid.IPWL Agam Solid merupakan LSM yang bergerak dalam bidang penanganan narkoba penting untuk terlibat dalam dukungan penyampaian sehingga dapat memberikan pemahaman pada penyalahguna untuk segera mendapat rehabilitasi.Institusi ini bertugas menerima laporan pecandu yang secara ikhlas melaporkan dirinya untuk direhabilitasi agar terlepas dari ketergantungan narkoba.

Program IPWL yang akan peniliti teliti yaitu IPWL yang berada di Jalan.Surau Usang Jorong Parit Putus Nagari Ampang Gadang. Kec.IV Angkek Kab. Agam, yang di dirikan pada tahun 2018. Program Institusi Penerima Wajib Lapor (IPWL) berdiri di latar belakangi oleh semakin banyaknya pengguna dan pecandu narkotika di kabupaten Agam. Berdirinya IPWL diperkuat dengan peraturan pemerintah No. 25 tahun 2011 tentang pelaksanaan wajib lapor bagi pecandu Narkoba dalam mendapatkan pelayanan rehabilitasi.Dimana dengan melapor ke IPWL maka pecandu narkotika bisa bebas dari jeratan hukum. Selain itu, pendekatan kepada pecandu narkotika adalah langkah yang tepat untuk memutus rantai obat melalui kebijakan/pendekatan kesehatan masyarakat sehingga pulih kembali.

Program ini diharapkan agar pecandu narkoba di Sumatera Barat khususnya di Agam dapat melapor dan melakukan rehabilitasi di IPWL Agam tersebut. Pada saat ini tenaga medis yang aktif di lembaga IPWL Agam tersebut berjumlah 2 orang, konselor 5 orang dan pengelola 2 orang. Dari awal berdiri sampai sekarang jumlah orang yang telah di rehabilitasi di Lembaga IPWL Agam Solid tersebut berjumlah 79 orang.

Institusi Penerima Wajib Lapor (IPWL) khusus untuk kabupaten Agam dengan nama IPWL Agam Solid telah ditunjuk 
sebagai institusi untuk melaksanakan rehabilitasi bagi pecandu melalui keputusan kemensos RI no. 43 / HUK / 2018 telah melaksanakan proses rehabilitasi sosial periode 2019 dimana sumber daya manusia yang bertugas di IPWL Agam solid telah berhasil menjangkau kliendari latar belakang yang berbeda. Untuk melaksanakan tugas rehabilitasi pengguna narkotika tersebut IPWL Agam Solid bekerja sama dengan lembaga Swadaya Masyarakat Ganggam Solidaritas, Hal ini berdasarkan surat kepala Dinas Sosial kab. Agam No. 460 / 1265 / sosial - 2017 tanggal 12 September 2017 perihal rekomendasi, dengan ini menyatakan Izin diberikan kepada LSM Ganggam Solidaritas untuk melaksanakan kegiatan penyuluhan bahaya narkotika dan sejenisnya, serta mebuat panti rehabilitasi korban pemakaian narkoba dan sejenisnya.

Sejauh ini di kalangan masyarakat informasi IPWL masih sangat minim.Padahal program dari lembaga ini sangat banyak manfaatnya bagi pengguna NAPZA. Oleh karena itu, perlu ditingkatkan lagi kualitas pelayanan agar dapat menjadi solusi dalam pemecahan masalah yang dialami korban penyalahgunaan NAPZA. Dikarenakan masih kurangnya sosialisasi yang diberikan kepada masyarakat tentang IPWL, masih banyak masyarakat kab. Agam khususnya yang masih belum mengetahui tentang IPWL.

Bagi para korban pelahgunaan NAPZA dapat memanfaatkan IPWL untuk membantu mereka agar dapat berubah dan di reahabilitasi dengan cara mendaftar ke IPWL dan mendapatkan kartu peserta. Dimana jika ada tersangka yang mempunyai kartu peserta tertangkap, maka akan ditangani sesuai dengan Peraturan Pemerintah.

Tapi pada implementasinya berbeda yang ditemukan oleh peneliti.Dimana permasalahan yang ada, para korban penyalahgunaan NAPZA menyalahgunakan kartu peserta agar terhindar dari kasus hukum.Selain itu peneliti menemukan bahwa dalam pelaksanaannya, para pengguna NAPZA yang sedang di rehabilitasi menggunakan program rawat jalan masih kurang maksimal.Pengguna NAPZA yang telah di rehab, mereka di bebaskan kembali begitu saja dan tidak ada tuntutan untuk kembali melakukan rehab. Hal tersebut bisa saja pengguna NAPZA yang telah melakukan rehab rawat jalan kembali menggunakan barang terlarang itu.

\section{TINJAUAN PUSTAKA \\ Konsep Efektivitas}

Menurut Wicaksono (2016) Efektifitas adalah merupakan unsur utamadalam mencapai sasaranyang sudah diidentifikasi di setiap organisasi. Program di sebut efektif jika dipenuhi dengan tujuan tertentu. Menurut Hidayat dalam (sitti yunita kadir, 2017) Efektivitas adalah ukuran sejauh mana tujuan telah tercapai. Semakin tinggi persentase target yang dicapai, maka efektivitasnyaakan tinggi juga.

Menurut Robbins dalam (Sari \& Sumarti, 2017) Efektifitas adalah tingkat pencapaian organisasi baik jangka pendek ataupun jangka panjang. Ini sesuai dengan pendapat menurut Bastian dalam (Nawawi, 2015, p. 190) bahwa efektivitas yaitu hubungan antara output, di mana mengukur efektivitas didasarkanseberapa jauh kebijakan dari organisasi mencapai tujuan yang telah ditentukan.

Menurut Sinungan dalam (Aziz et al., 2016) mengemukakan beberapa konsep efektivitas yaitu :

a) Efektivitas mengacu pada hubungan antara teori organisasi modern dan klasik;

b) Efektivitas dipandang seperti perbandingan antara tingkatan, di mana tujuan dinyatakan dapat tercapai;

c) Efektivitas/perbandingan eksternal antara unit output dan penilaian unit input;

d) Efektivitas adalah kemampuan sistem yang berlangsung tepat terlepas dari tujuan spesifik yang akan dicapai. 
Dari definisi diatas efektifitas adalah sebuah pengukuran yang menunjukkan seberapa jauh hasil yang telah dicapai baik itu dari segi kuantitas, target dan waktu .

\section{Konsep Rehabilitasi}

Menurut Tarmansyah (2003; 41) Rehabilitasi merupakan rangkaian kegiatan yang bertujuan untuk mencegah, meningkatkan, menyembuhkan dan menyediakan serta memulihkan kapasitas masyarakat yang membutuhkan pelayanan khusus. Rehabilitasi jika dikaji dari arti kata yang berasal dari bahasa Inggris yaitu rehabilitasi yang berarti kembali seperti rawal sebelumnya, kembalinya makna adalah mengembalikan kemampuan yang pernah ada, karena yang hilang adalah apa yang dikembalikan seperti sebelum bencana yang terjadi Rehabilitasi adalah upaya untuk memberikan layanan kepada orangorang yang membutuhkan layanan khusus dari berbagai jenis tergantung pada gangguan yang dialaminya.

\section{Konsep Narkotika}

Menurut Undang-undang nomor 35 Tahun 2009 tentang narkotika, narkotika adalah obat yang berasal dari tanaman atau bukan tanaman dapat menyebabkan penurunan kesadaran, menghilangkan rasa sakit, dan dapat menyebabkan ketergantungan.

Narkotika adalah berguna juga untuk pengobatan penyakit tertentu. Namun, jika disalahgunakan dapat memiliki konsekuensi negatif bagi individu atau banyak orang, terutama angkatan muda. Hal ini jika disertai dengan peredaran gelap narkotika, bisa merusak serta membahayakan kehidupan bangsadan melemahkan ketahanan nasional. (sujoro, 2009, p. 59)

Berdasarkan teori tersebut dapat disimpulkan dalam peredarannya, narkotika perlu diawasi oleh pemerintah, sehingga tidak ada celah bagi para pengguna narkotika dalam menyalahgunakan narkotika. Dan diharapkan masyarakat jauh dari efek samping bahaya narkotika tersebut.

\section{Konsep Kendala dan Solusi}

\section{A. Konsep Kendala}

Hansen dan Mowen dalam Styaningrum \& Hamidi (2002:28) dikutip dari skripsi (ashari, 2016), kendala dapat digolongkan berdasarkan asalnya dan sifatnya.

a. Berdasarkan Asalnya
1) Kendala Internal (Internal Constraint) adalah faktor yang membatasi sistem organisasi sistem dari perusahaan. Hal ini digunakan secara maksimal tanpa meningkatkan biaya operasi.
2) KendalaEksternal(external constraint)ialah faktor yang dibatasidari luar perusahaan. Juga dapat ditafsirkan berasal dari luar organisasi atau sistem.

b. Berdasarkan Sifatnya
1) Kendala mengikut (binding constraint) adalah mengandung sumber daya yang telah dimanfaatkan seluruhnya.
2) Kendala yang tidak mengikat ialah sumber daya dibatasi atau tidak sepenuhnya digunakan.

Kaplan dan Atkinson menambahkantiga pengelompokkan kendala yaitu :

1) Kendala sumber daya (resource constaint), dapat berupa kemampuan produksi seperti bahan baku, tenaga kerja dan jam mesin.

2) Kendala pasar(market resource), merupakan tingkat minimum dan maksimum penjualan dimungkinkan selama periode perencanaan.

3) Kendala keseimbangan (balance constaint), diidentifikasi sebagai siklus produksi.

\section{B. Konsep Solusi}

Dengan menerapkan ide sebagai solusi untuk sebuah masalah, Goldratt telah memaparkan lima langkah untuk membuat proses perbaikan lebih fokus untuk sistem adalah: 
1) Identifikasi konstrain system (identifying theconstraint). Mengidentifikasi bagian system kebijakan yang lemah.

2) Ekploitasi konstrain (exploiting theconstraint). Menentukan cara untuk mengelola kendala dengan biaya paling minim.

3) Subordinasi sumber lainnya (subordinating the remaining resource). Setelah menentukan kendala dalam pengelolaannya, apakah masih terkendala pada kinerja sistem.

4) Evaluasi kontrain (Elevating the constraint). Jika ini dilakukan, maka langkah kedua dan ketiga gagal terhadap pengelolaan rintangan. Kemudian terjadi perubahan besar dalam sistem.

5) Mengulangi proses keseluruhan (repeating the process). Apabila langkah ketiga dan keempat berhasil dilakukan, maka harus diulangi dari langkah pertama. Proses ini bisa berubah seperti siklus. Harus waspada kepada solusiseketika dapat menyebabkan kendala yang baru.

\section{Konsep Program Institusi Penerima Wajib Lapor (IPWL)}

Arikunto dan Jabar (2009:3) dalam (Munthe, 2015) ada beberapa penjelasan untuk istilah program merupakan suatuperencanaan yang harus dijalankan. Jika suatu program berkaitan langsung dengan penerapan kebijakan dapat dimaknai sebagai suatu kegiatan yang melibatkan banyak orang.

Arikunto (Munthe, 2015) menyatakan program memiliki tiga makna penting yang harus ditekankan, yaitu (1) yang membuat aturan; (2) berjalan dalam kurung waktu yang lama, yang merupakan kegiatan jamak yang berkelanjutan; dan (3) terjadidi organisasi yang meingikutsertakan sekelompok orang. Program diartikan sebagaisatuan kegiatan yang dapat dilaksanakan tidak hanya sekali tetapi terus menerus.

Menurut Tayibnapis (Munthe, 2015) sebuah program adalah segala suatu yang coba dilakukan seseorang dengan mengharapakan membawa hasil. Menurut Widoyoko, program ini didefinisikan sebagai rangkaian terencanadengan cermat berlangsung dalam sebuah organisasi yang melibatkan beberapa orang.

Program Pemerintah yang menjadi fokus kajian penelitian yaitu IPWL merupakan kelembagaan yang berdasarkan peraturan pemerintah Nomor 25 Tahun 2011 tentang pelaksanaan wajib lapor bagi pecandu Narkotika. Institusiini ialah implementasi Undang-Undang Nomor 35 Tahun 2009 pasal 55 ayat 1 dan 2 tentang Narkotika, bahwa pecandu penyalahgunaan narotika wajib menjalani rehabilitasi medis dan sosial.

Institusi Penerima Wajib Lapor didefenisikan sebagai kegiatan pelaporan yang dilakukan oleh pecandu narkotika yang sudah cukup umur atau belum kepada lembaga penerima wajib lapor sehingga mendapatkan perawatan melalui rehabilitasi medis dan sosial. IPWL ini ialah fasilitas rehabilitasi medis dan sosial yang ditunjuk pemerintah untuk pengembangan seseorang secara wajar menjalankan fungsi sosialnya dalam kehidupan bermasyarakat (Undang-UndangNomor 11 Tahun 2009).

\section{METODE PENELITIAN}

Jenis penelitian yang digunakan kualitatif dengan metode deskriptif yang yang berusaha menggambarkan fenomena yang terjadi di masa kini. Menurut Bogan dan Taylor dalam (Moleong lexy J, 2006, p. 4) penelitian kualitatif adalah penelitian yang menghasilkan data deskriptif dalam bentuk kata tertulis atau perilaku seseorang yang dapat diteliti. Focus penelitian ini yaitu pelaksanaan Program Kerja IPWL Agam Solid terhadap pecandu dan pengguna NAPZA, efektivitas Program IPWL Agam Solid terhadap pecandu dan pengguna NAPZA dan juga kendala dan hambatan yang ditemukan oleh IPWL 
Agam Solid dalam rehabilitasi bagi pecandu dan pengguna NAPZA. Lokasi penelitian dilakukan di Kabupaten Agam tepatnya di Jln. Surau Usang, Jorong Parit Putus, Nagari Ampang Gadang, Kecamatan IV Angkek.Untuk teknik pengumpulan data yang penulis pakai dalam pengumpulan data yaitu wawancara, observasi, serta studi dokumentasi.Uji keabsahan data menggunakan trianggulasi sumber dan teknik analisis data menggunakan reduksi, penyajian dan verifikasi data.

\section{HASIL DAN PEMBAHASAN}

Berdasarkan pembahasan yang sudah dipaparkan sebelumnya, jadi bisa disimpulkan dua hal sebagai berikut.

\section{Pelaksanaan Program kerja IPWL Agam Solid Dalam Rehabilitasi Pecandu dan Pengguna Napza}

Pada objek penelitian ini, IPWL Agam Solid terbukti sebagai lembaga yang memberikan pelayanan rehabilitasi pada korban penyalahgunaan obat obatan sesuai dengan prosedur yang telah ditetapkan dalam Undang-Undang no 35 tahun 2009 serta berdasarkan Keputusan Menteri Kesehatan (Kepmenkes) Nomor 1305/Menkes/VI/2011 tentang Institusi Penerima Wajib Lapor (IPWL). Prosedur tersebut ialah Rehabilitasi Sosial yang meliputi Rawat Inap dan Jalan Dari tingkat keberhasilan Rehabilitasi, IPWL Agam Solid dinilai terlah berhasil dalam melaksanakan proses rehabilitasi dan sukses untuk membuat pengguna narkoba tidak menggunakan obat obatan lagi. Namun jika ditinjau dari jumlah peserta rehabilitasi yang sudah produktif masih sangat sedikit.Dimana dapat diartikan bahwa IPWL memang sudah membantu pengguna narkoba agar menjauhi obat obatan.Namun masih belum efektif dalam menunjang agar mantan pecandu narkoba dapat bekerja dan hidup seperti biasa.

\section{Efektifitas Program Kerja IPWL terhadap Peserta Rehabilitasi Narkoba}

Indikator dari efektivitas menurut (Tika et al., 2019) terdapat empat indikator dalam mengukur efektivitas yaitu:

a. Pencapaian Target di sini berarti bahwa sejauh mana tujuan dapat ditetapkan oleh organisasi tercapai dengan benar.

b. Kemampuan Adaptasi Keberhasilan suatu organisasi disebabkan oleh selama organisasi dapat beradaptasi ke yang lebih baik di dalam maupun di luar organisasi tersebut.

c. Kepuasan Kerja Sebuah keadaan yang dirasakan seluruh anggota organisasi yang bisa menawarkan motivasi untuk meningkatkan kinerja organisasi. Berfokus pada pekerjaan anggota organisasi yang mempunyai prestasi di luar beban kerja yang ada.

d. Tanggung jawab suatu organisasi yang amanah dapat dipenuhinya sesuai dengan ketentuan yang telah dibuat sebelumnya serta bisa mengatasi permasalahan yang timbul dalam pekerjaannya.

Berdasarkan paparan diatas dapat dijadikan pedoman untuk mengukur seberapa jauh tingkat efektivitas IPWL Agam Solid dalam melaksanakan program kerja. Dari segi Kemampuan adapatasi pun IPWL Agam Solid dapat beradaptasi dengan berbagai karakter dari peserta rehabilitasi dan menyesuaikan pendekatan dan program paling baik untuk masing masing peserta rehab.Kepuasan kerja dan tanggung jawab lembaga dalam mengayomi dan melaksanakan rehabillitasipun cukup baik namun sayangnya jika ditinjau dari target, IPWL Agam Solid masih belum memenuhi target Rehabilitasi korban karena masih sedikitnya korban penyalah gunaan obat obatan dalam melaporkan dirinya.Dan juga IPWL Agam Solid masih banyak terkendala dengan fasilitas seperti pelatihan untuk peserta rehabilitasi dan peralatan medis untuk melayangi keadaan gawat darurat.Maka dari pada itu dapat 
disimpulkan bahwa kinerja dari IPWl Agam

Solid masih berlum begitu efektive dikarenakan kurangnya Sumberdaya.

\section{Kendala dalam Kinerja IPWL Agam Solid}

Kendala kendala dalam kinerja IPWL sebelumnya pernah ditelitu oleh (Unayah, 2016) tentang Peraturan Presiden RI Nomor 25 Tahun 2011 Tentang Pelaksanaan Wajib Lapor Pecandu Narkotika masih memiliki kendala seperti: 1) pengetahuan masyarakat yang sedikit terhadapIPWL; 2) terbatasnya perbandingan jumlah target populasi; 3) sedikitnyadaya tampug kelembagaan IPWL; 4) rendahnya tingkat kepercayaan korban terhadap IPWL atas kerahasiaan data mereka tidak dipidana; 5) belum adanya SOPIPWL. Pada penelitian inipun penulis masih menemukan kendala yang sama pada IPWL Agam Solid dalam melaksanakan program kerja.

Berdasarkan paparan diatas dapat disimpulkan bahwa kendala yang paling besar itu adalah minimyanya kepercayaan korban kepada IPWL atas kerahasiaan data bahwa mereka tidak akandipidana. Hal ini menyebabkan banyak dari korban/keluarga korban penyalahgunaan obat obatan menjadi enggan untuk mengambil tindakan dnegan alasan takut akan terkena hukum pidana, justru sebenarnya akan sangat baik sekali apabila keluarga atau korban melaporkan dnegan suka rela, hal ini akan meringankan proses berjalannya hukum dan juga proses rehabilitasi pun akan berjalan dengan mudah. Komunikasi dan pendekatan antara pihak IPWL dan keluarga/korban akan berjalan dua arah dan sangat lancar. Kesembuhan dari korbanpun akan segera pulih dikarenakan adanya dukungan nyata dari kelurarga. Kendala kedua adalah terbatasnya dana dan sumberdaya dalam menciptakan pelatihan pelatihan untuk korban penyalah gunaan narkoba selama proses rehabilitasi berlangsung. Kurangnya pelatihan membuat korban penyalahgunaan narkoba menjadi sulit dalam memasuki dunia kerja dikarenakan rendahnya skill dan catatan buruk sebagai mantan pecandu narkoba.

\section{PENUTUP}

Hasil penelitian dan pembahasan yang dipaparkan, dapat disimpulkan bahwa:

1. Pelaksanaan Program Kerja pada IPWL Agam Solid adalah bebasis Rehabilitasi Sosial, Dimana Rehabilitasi Sosial tersebut terbagi menjadi dua kategori yaitu, Rawat Inap dan Rawan Jalan. Dari segi penyediaan konseling dan terapi keduanya tidak ada bedanya.Hanya saja berbeda dalam tingkat intensitas, Rehabilitasi rawat inap dinilai jauh lebih intens dibandingkan dengan rawat jalan yang hanya mengadakan pertemuan konseling kurang kira kira dua kali dalam sebulan.Namun, pada pelaksanaanya, Rehabilitasi Rawat Jalan lah yang paling banyak dilaksanakan oleh peserta rehabilitasi di IPWL AGAM SOLID.

2. Efektivitas Kinerja IPWL Agam Solid sudah dinilai efektif dikarenakan berhasil dalam melaksanakan kegiatan Rehabilitasi Sosial para pencandu obat obatan. Namun, jika dinilai dari segi efisiensi bisa dikatakan masih belum optimal.Pada kenyatannya, pencandu narkoba memang telah berhenti menggunaka obat obatan setelah menyelesaikan kegiatan rehabilitasi di IPWL.Namun, mereka masih memiliki kendala untuk berbaur kembali dengan masyarakat serta beraktifitas seperti biasa, karena image seorang pecandu yang melekat dan membebani.

3. Kendala yang paling besar dialami oleh IPWL Agam Solid adalah minimnya kepercayaan korban atas kerahasiaan data bahwa mereka tidak akandipidana. Kendala yang kedua adalah terbatasnya dana dan sumberdaya dalam menciptakan pelatihan pelatihan untuk korban penyalahgunaan narkoba selama proses rehabilitasi berlangsung. Kendala ketiga adalah kurangnya pelatihan membuat korban 
penyalahgunaan narkoba menjadi sulit dalam memasuki dunia kerja dikarenakan rwndahnya skill dan catatan buruk sebagai mantan pecandu narkoba.

\section{DAFTAR KEPUSTAKAAN}

Ashari, okta vera. (2016). Efektivitas Pengelolaan Data Elektronik (EPD)di kantor bupati kabupaten padang pariaman.

Aziz, E., Idi, A., \& Akhyar, T. (2016). Efektifitas Program Peningkatan Keterampilan Dan Kewirausahaan Anak Jalanan Di Kota Palembang. Jurnal Administrasi Publik.

Moleong lexy J. (2006). metodologi penelitian kualitatif. Remaja Rosdakarya.

Munthe, A. P. (2015). Pentingya Evaluasi Program Di Institusi Pendidikan: Sebuah Pengantar, Pengertian, Tujuan dan Manfaat. Scholaria: Jurnal Pendidikan Dan Kebudayaan. https://doi.org/10.24246/j.scholaria.20 15.v5.i2.p1-14

Nawawi, zaidan. (2015). manajemen pemerintahan. Rajawali Pers.

Sari, D. P., \& Sumarti, T. (2017). Analisis Efektivitas Program Pemberdayaan Anak Jalanan di Rumah Singgah Tabayun Kecamatan Cibinong, Kabupaten Bogor. Jurnal Sains Komunikasi Dan Pengembangan Masyarakat [JSKPM]. https://doi.org/10.29244/jskpm.1.1.2942

Sitti yunita kadir. (2017). efektivitas kinerja pegawai di badan kesatuan bangsa dan politik provinsi maluku utara. JURNAL EKSEKUTIF, 01 .

Sujoro, A. (2009). komentar dan pembahasan UU narkotika. Sinar
Grafika.

Tika, E. D., Ritonga, S., \& Dewi, R. (2019). Efektivitas Kinerja Klinik Pratama Badan Narkotika Nasional Provinsi Sumatera Utara dalam Merehabilitasi Rawat Jalan Pecandu Narkotika. PERSPEKTIF.

https://doi.org/10.31289/perspektif.v8i 1.2542

Unayah, N. (2016). Institusi (Penerima) Wajib Lapor Dalam Penanganan Korban Penyalahgunaan Narkotika: Tantangan Dan Solusi Alternatif. Sosio Informa.

https://doi.org/10.33007/inf.v2i2.218

Undang-Undang Nomor 35 Tahun 2009 pasal 54-58 Tentang Narkotika

Peraturan Pemerintah Nomor 25 Tahun 2011 Tentang Pelaksanaan Wajib Lapor Bagi Pecandu Narkotika 